\title{
Assessment of refractive outcome of femtosecond-assisted LASIK for hyperopia correction
}

Mohamed Tarek El-Naggar, Dikran Gilbert Hovaghimian

Researcher, Research Institute of Ophthalmology, Giza, Egypt

Type of article: Original

\begin{abstract}
Introduction: Laser vision correction for hyperopia is challenging. The purpose of the study was to assess the refractive outcomes of femtosecond-assisted laser in situ keratomileusis (LASIK) for hyperopic correction using wavefront-optimized ablation profiles.

Methods: This retrospective case series study included 20 Egyptian patients (40 eyes) with hyperopia or hyperopic astigmatism with a mean manifest refraction spherical equivalent (MRSE) of $+2.55 \mathrm{D} \pm 1.17$ (range from +1.00 to +6.00 ) who had uneventful femtosecond-a assisted LASIK with wavefront-optimized aspheric ablation profile using refractive surgery suite (WaveLight FS200 Femtosecond Laser and WaveLight EX500 Excimer Laser) performed in the Research Institute of Ophthalmology and International Eye Hospital, Giza, Egypt. Statistical analysis was done using Microsoft Excel (Microsoft Corporation, Seattle, WA, USA).

Results: The procedure significantly reduced the MRSE and cylinder post-operatively $(95 \%$ were $\pm 0.50 \mathrm{D}$ and $100 \% \pm 1.00 \mathrm{D}$ ), with stability of refraction and UDVA over the follow-up period (up to 12 months) after surgery. No eye lost any line of the CDVA, which reflects the excellent safety profile of the procedure; on the other hand, one eye $(5 \%)$ gained one line and one eye $(5 \%)$ even gained two lines. There were no significant complications during the procedure.

Conclusions: Femtosecond-assisted laser in situ keratomileusis for hyperopia showed predictable, effective, and safe refractive outcomes that were stable through 12 months. Longer follow-up period is required to detect any further regression

Keywords: Hyperopia correction, Femtosecond LASIK, Refractive surgery, Refractive outcomes
\end{abstract}

\section{Introduction}

Hyperopic laser vision correction is considered challenging for refractive surgeons $(1,2)$. Although LASIK is considered by many refractive surgeons as the preferred technique, hyperopic correction presents additional challenges, starting from accurate detection of patient manifest refraction and integration of the cycloplegic refraction in this process followed by accurate centeration (1-9). Basically, the aim of excimer laser photo ablation in the case of hyperopic correction is to induce relative steepening in the central part of the cornea; this target is achieved by an annular ablation profile, which induces more flattening in the corneal periphery; thus, it is considered more challenging than the myopic ablation, which induces direct flattening in the corneal central area $(1,3)$. Another difficulty is that hyperopic correction ablation time is longer than the equivalent dioptric correction for myopic refraction, which makes it more sensitive to patient eye movement and requires an accurate and fast eye-tracker in order to ensure that you place your laser ablation in the planned location (2); this problem may be further complicated by the fact that most of the patient who are seeking hyperopic refractive surgery are relatively old, so they may have a problem in fixation to a near target during ablation due to the presbyopic element, which may lead to de-centeration of the ablation. This problem is largely overcome by the newer, accurate eye-trackers combined with faster excimer laser systems $(10,11)$. Another dilemma is where to center the ablation profile: the corneal vertex, the pupil center, or somewhere in between in order to estimate the true visual axis; the problem is even exaggerated in these patients, as they usually have a wider-angle Kappa $(10,11)$. Higher incidence of epithelial

\section{Corresponding author:}

Dr. Tarek Elnaggar, Research Institute of Ophthalmology, Giza, Egypt.

Tel: +20.1222158593, Email: drtarekelnaggar@hotmail.com

Received: October 02, 2016, Accepted: February 18, 2017, Published: March 2017

iThenticate screening: February 12, 2017, English editing: March 04, 2017, Quality control: March 10, 2017

(C) 2017 The Authors. This is an open access article under the terms of the Creative Commons Attribution-NonCommercialNoDerivs License, which permits use and distribution in any medium, provided the original work is properly cited, the use is non-commercial and no modifications or adaptations are made. 
ingrowth as the ablation occurs in the periphery adjacent to the flap edge so the epithelium might find a way under the flap to the deep ablated zone (12). Greater tendency of regression has been reported $(5,13)$, which may be explained by postoperative loss of accommodative spasm, mechanical instability of corneal tissue biomechanics, and/or irregular epithelial remodeling over the ablation zone (13). Several advancements in hyperopic LASIK technique have been applied to overcome some of the previously mentioned problems, including a larger optical zone, which requires larger flap making, nomogram refinement, and proper centration (13). In our study, we assessed the refractive outcomes of femtosecond assisted hyperopic LASIK performed for the correction of low to moderate hyperopia.

\section{Material and Methods}

\subsection{Setting and study design}

This retrospective study comprised 20 Egyptian patients (12 females and eight males) who had femtosecond laserassisted hyperopic LASIK using refractive surgery suite (WaveLight FS200 Femtosecond Laser and WaveLight EX500 Excimer Laser; Alcon Laboratories, Ft Worth, TX, USA), between January 2012 and September 2013 in the Research Institute of Ophthalmology and International Eye Hospital, Giza, Egypt. The mean age of the patients was 47.2 \pm 3.84 (ranging from 42 to 56 years); all treatments were performed by the same surgeon (T.N).

\subsection{Selection criteria}

Inclusion criteria included a postoperative follow-up of at least 12 months and preoperative stable refraction for at least one year, normal corneal tomography with expected postoperative steep $\mathrm{K}$ reading not more than $48 \mathrm{D}$, and postoperative residual stromal bed not less than $300 \mu \mathrm{m}$. Exclusion criteria included a preoperative CDVA of worse than 20/30, previous ocular surgeries, and corneal, uveal or retinal diseases. Amblyopic patients and glaucoma patients were also excluded.

\subsection{Preoperative examination and follow-up}

The preoperative examination included measuring uncorrected distance visual acuity (UDVA), corrected distance visual acuity (CDVA), manifest and cycloplegic refractions; full ophthalmological examination included slitlamp biomicroscopy, Goldmann applanation tonometry, and full fundus evaluation. Corneal tomography with placidobased topolyzer vario topography (WaveLight, Erlangen, Germany) and Scheimpflug-based imaging system (Pentacam, Oculus Optikgeräte $\mathrm{GmbH}$ ) were also performed in all cases. Postoperative follow-up examinations were conducted at 1 day, 1 week, 1 month, 3 months, 6 months, and 1 year.

\subsection{Surgical technique}

Prior to the surgery, topical benoxinate hydrochloride $0.4 \%$ was instilled into the eyes. A lid speculum was used to open the eyelid. Femtosecond flap creation with a WaveLight FS200 femtosecond laser system was performed with intended flap diameter of $9.3 \mathrm{~mm}$ to allow a large ablation zone and transitional zone, an attempted flap thickness of $120 \mu \mathrm{m}$ with superior hinge and side angle cut of 120 degrees. Excimer laser photo ablation was performed after lifting the femtosecond created flap using a WaveLight EX500 excimer laser system with an optical zone of $7 \mathrm{~mm}$. The treatment was centered on the corneal vertex when the difference between the pupil centroid and corneal vertex was less than $0.30 \mathrm{~mm}$, which was measured by the topolyzer vario topography (WaveLight, Erlangen, Germany).

\subsection{Ethics}

This study was approved by the Institutional Review Board and adhered to the tenets of the Declaration of Helsinki.

\subsection{Analyses}

Statistical analysis and graphs were done with standard spreadsheet software program using Microsoft Excel 2013 (Microsoft Corporation, Seattle, WA, USA).

\section{Results}

To assess the refractive outcome of the procedure, UDVA, CDVA, MRSE, manifest refractive cylinder, and stability were compared preoperatively and 1 week and 1, 3, 6, and 12 months postoperatively. Following the recommendation of Waring et al. for standardized graphs and terms for refractive surgery results, the data were plotted in set of six standard graphs summarizing efficacy, predictability, safety, refractive astigmatism, and stability using Microsoft Excel templates (Microsoft Corporation, Seattle, WA, USA) designed by London Vision Clinic (London, W1G 7LA, UK). Regarding the efficacy, as shown in Figure 1, the preoperative CDVA compared with 12 months' postoperative UDVA showed that all the 20 eyes (100\%) reached UDVA of 20/25 or better, and 17 eyes 
(85\%) reached 20/20 of UDVA, which reflected excellent efficacy of the procedure. In Figure 2 preoperative and postoperative CDVA were analyzed, and the visual acuity lines gain and loss were plotted showing that no eye lost any line of the CDVA, which reflected excellent safety of the procedure; on the other hand, one eye (5\%) gained one line and one eye $(5 \%)$ even gained two lines; these results reflect potential extra benefits of the procedure and might be explained by the correction made on the corneal level, which is optically better than that on the glasses level and might be related to aberrations induced by the hyperopic magnifying plus lens used to correct hyperopia.

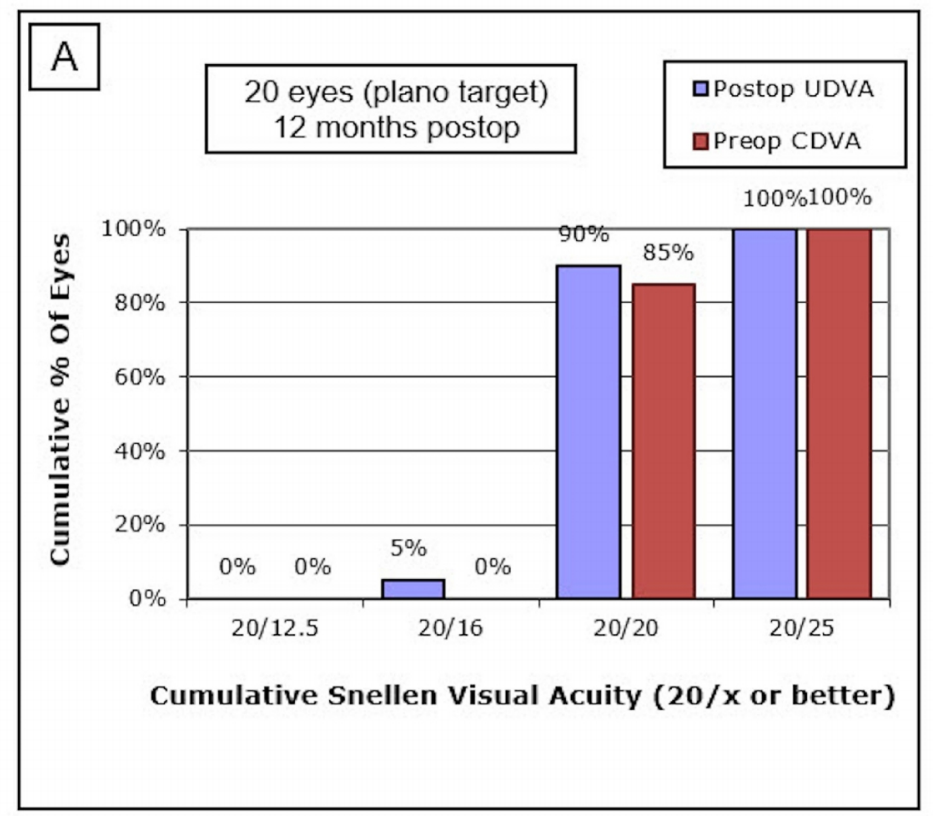

\section{Uncorrected Distance Visual Acuity}

Figure 1. Preoperative CDVA (RED) compared with 12 months' postoperative UDVA

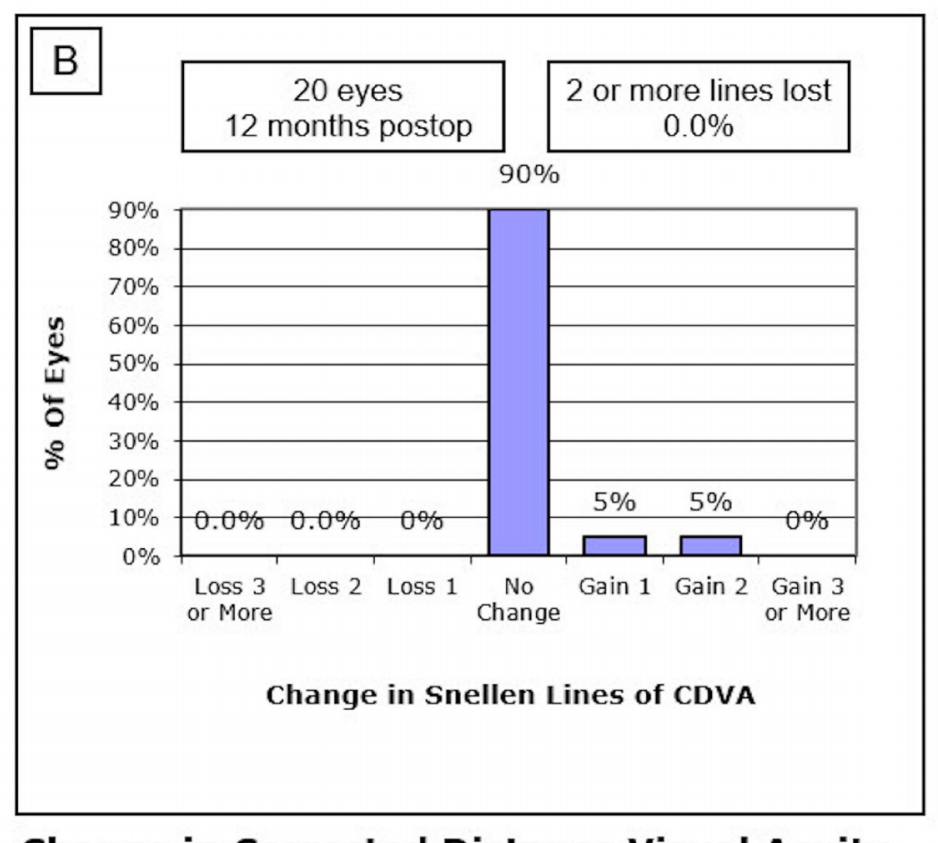

\section{Change in Corrected Distance Visual Acuity}

Figure 2. The change of the CDVA 12 months postoperatively 
Predictability and refractive accuracy: Predictability was directly associated with a lower standard deviation (SD) and standard error of the SE deviation from the target at any point and a better tightness of fit of the attempted SE versus the achieved SE plot (reflected by the correlation coefficient R2 $=0.947$ ). The procedure showed good predictability, as shown in Figure 3. The scattergram comparing the achieved spherical equivalent refraction versus the attempted spherical equivalent refraction of every eye showed that all the eyes were within $+/-1.00 \mathrm{D}$ postoperatively, and 95\% (19 eyes) were within +/-0.50 D 12 months postoperatively. Further assessment of the refractive accuracy was analyzed; Figure 4 shows the exact distribution of the 12 months' postoperative UDVA in the whole series.

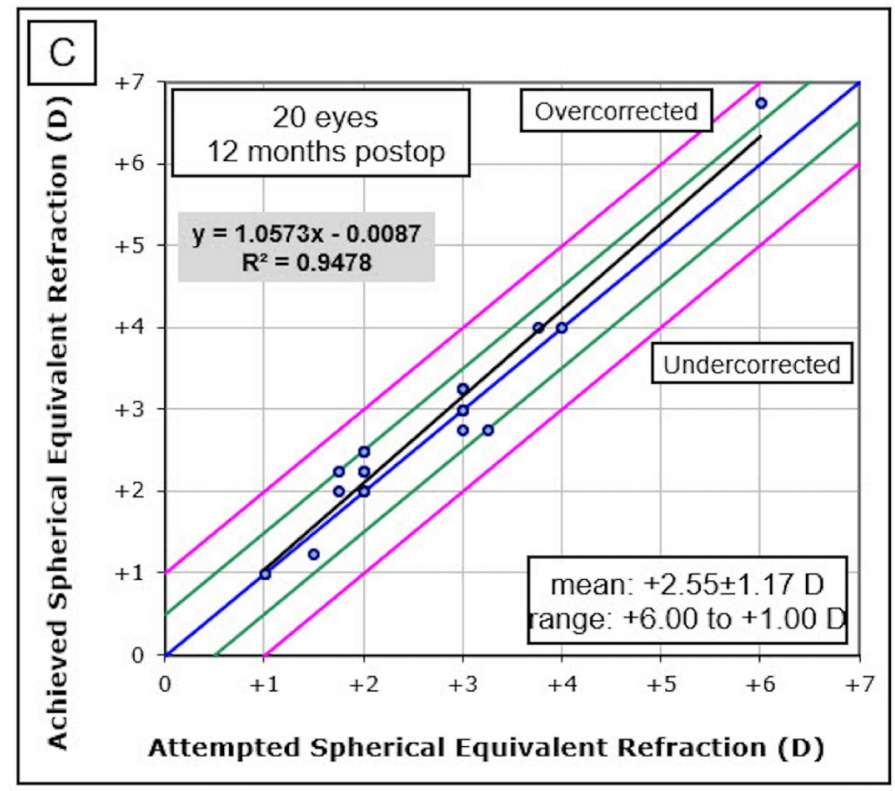

\section{Spherical Equivalent Attempted vs Achieved}

Figure 3. Scattergram comparing achieved spherical equivalent refraction 12 months' postoperatively ( $Y$ axis $)$ and attempted spherical equivalent refraction ( $X$ axis)

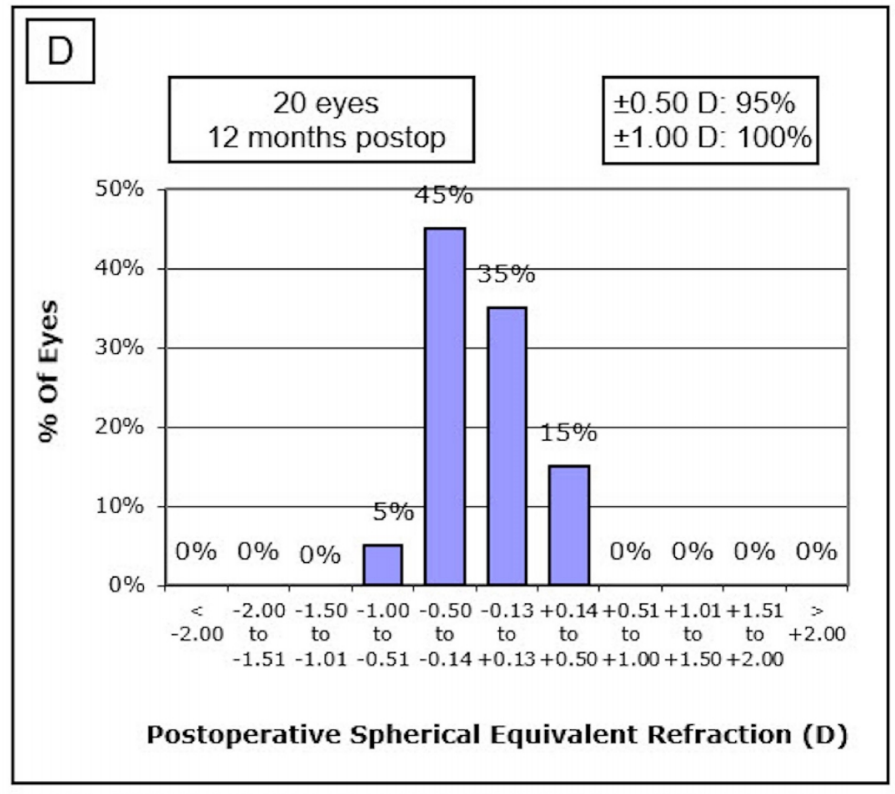

\section{Spherical Equivalent Refractive Accuracy}

Figure 4. Refractive accuracy expressed in postoperative spherical equivalent 
Figure 5 shows a comparison between the preoperative refractive astigmatism and 12 months' postoperative refractive astigmatism, $85 \%$ of the eyes (17 eyes) had less than or equal to $1 \mathrm{D}$ of astigmatism 12 months postoperatively, and $30 \%$ (six eyes) had less than or equal to $0.5 \mathrm{D}$ astigmatism 12 months postoperatively. Stability was defined as the repeatability of first week postoperative spherical equivalent refraction over the 12 months of follow-up. Figure 6 shows the stability curve over the 12 months' follow-up period which was excellent.

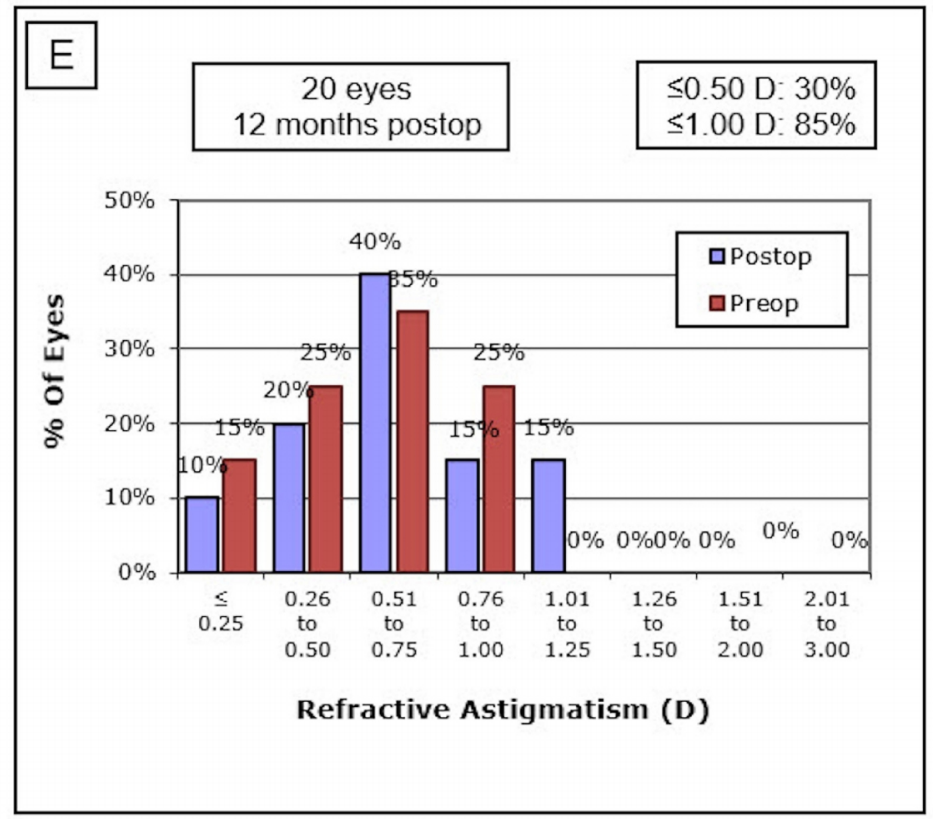

\section{Refractive Astigmatism}

Figure 5. Twelve months' postoperative astigmatism (blue) compared to preoperative astigmatism (red)

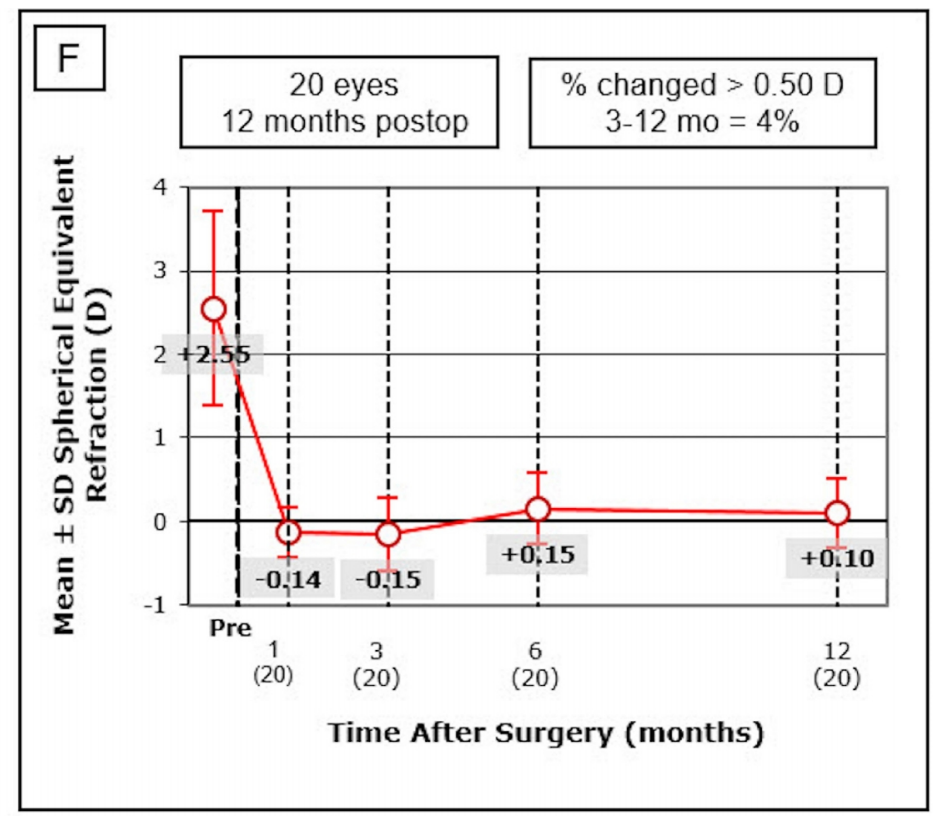

\section{Stability of Spherical Equivalent Refraction}

Figure 6. Stability over 12 months' follow-up 


\section{Discussion and conclusions}

As previous studies reported better refractive results with femtosecond laser flap creation than with mechanical microkeratome flap creation $(14,15)$, the purpose of this study was to evaluate the refractive outcome of femtosecond-assisted LASIK for the correction of hyperopia using the Alcon-WaveLight FS200 femtosecond laser system and the Allegreto EX500 as using a femtosecond laser in flap creation has potential benefits, as it creates a smoother stromal bed under the created flap, which is assumed to yield better refractive outcomes after laser refractive surgery (14-25). In this study, a flap creation as large as $9.3 \mathrm{~mm}$ was intended to allow accurate placement of the peripheral laser ablation inside the stromal bed and avoid hitting the peripheral epithelium, which eventually will regenerate with no refractive effect, leading to a more accurate and potentially more stable ablation. A planar flap results in less cutting of peripheral stromal fibers (14-25). In addition, the stroma bed is relatively dry after flap lifting, which may improve the efficacy of laser ablation, resulting in more optimal refractive outcome of hyperopia correction $(14,15,24)$. Further, strong adhesion of the flap in the postoperative period may produce a stronger biomechanical flap stability (20). Several studies $(3-9,13,15,26-32)$ reported the outcome of excimer laser photoablation to correct hyperopia with different platforms with variable follow-up periods. These studies showed a high safety profile of the procedure with good efficacy and predictability except in high hyperopic correction (13). It should be noted that evaluating refractive outcomes after hyperopic LASIK can be challenging, as some patients may still have some sort of accommodation power, and some of them did not wear glasses for distance and acquired some sort of accommodative spasm, which takes time to relax. Another important factor is that assessing refractive stability could be difficult because manifest refraction in hyperopic eyes can increase with age due to reduced ability to compensate for latent hyperopia, which could be falsely interpreted as regression of the procedure outcome. In our study, femtosecond-assisted LASIK appears to be safe, predictable, and effective in correcting eyes with hyperopia in the first week, and the results remain almost stable within the follow-up period (12 months). The small sample size might be a limiting factor in our study, and longer follow-up is needed for a better conclusion regarding stability of the procedure.

\section{Acknowledgments:}

We would like to acknowledge our families for their support and nursing stuff in the Research Institute of Ophthalmology and International Eye Hospital, Giza, Egypt. No author has a financial or proprietary interest in any material or method mentioned.

\section{Conflict of Interest:}

There is no conflict of interest to be declared.

Authors' contributions:

Both authors contributed to this project and article equally. Both authors read and approved the final manuscript.

\section{References:}

1) Sher NA. Hyperopic refractive surgery. Curr Opin Ophthalmol. 2001; 12(4): 304-8. doi: 10.1097/00055735-200108000-00011. PMID: 11507345.

2) O'Brart DP. The status of hyperopic laser-assisted in situ keratomileusis. Curr Opin Ophthalmol. 1999; 10(4): 247-52. doi: 10.1097/00055735-199908000-00005. PMID: 10621531.

3) Suarez E, Torres F, Duplessie M. LASIK for correction of hyperopia and hyperopia with astigmatism. Int Ophthalmol Clin. 1996; 36(4): 65-72. doi: 10.1097/00004397-199603640-00010. PMID: 9072516.

4) Esquenazi S. Five-year follow-up of laser in situ keratomileusis for hyperopia using the Technolas Keracor 117C excimer laser. J Refract Surg. 2004; 20(4): 356-63. PMID: 15307398.

5) Zadok D, Raifkup F, Landau D, Frucht-Pery J. Long-term evaluation of hyperopic laser in situ keratomileusis. J Cataract Refract Surg. 2003; 29(11): 2181-8. doi: 10.1016/S0886-3350(03)00416-4.

6) Jaycock PD, O'Brart DP, Rajan MS, Marshall J. 5-year follow-up of LASIK for hyperopia. Ophthalmology. 2005; 112(2): 191-9. doi: 10.1016/j.ophtha.2004.09.017. PMID: 15691550.

7) Varley GA, Huang D, Rapuano CJ, Schallhorn S, Boxer Wachler BS, Sugar A. LASIK for hyperopia, hyperopic astigmatism, and mixed astigmatism; a report by the American Academy of Ophthalmology. Ophthalmology. 2004; 111(8): 1604-17. doi: 10.1016/j.ophtha.2004.05.016. PMID: 15288995.

8) Spades L, Sabetti L, D’Alessandri L, Balestrazzi E. Photorefractive keratectomy and LASIK for the correction of hyperopia: 2-year follow-up. J Refract Surg. 2006; 22(2): 131-6. PMID: 16523830.

9) Alio J, Galal A, Ayala MJ, Artola A. Hyperopic LASIK with Esiris/ Schwind technology. J Refract Surg. 2006; 22(8): 772-81. PMID: 17061714. 
10) Zaldivar R, Oscherow S, Bains HS. Five techniques for improving outcomes of hyperopic LASIK. J Refract Surg. 2005; 21(5 Suppl): S628-S32. PMID: 16212293.

11) Cobo-Soriano R, Llovet F, Gonza lez-Lo pez F, Domingo B, Go mez-Sanz F, Baviera J. Factors that influence outcomes of hyperopic laser in situ keratomileusis. J Cataract Refract Surg. 2002; 28(9): 1530-8. doi: 10.1016/S0886-3350(02)01367-6. PMID: 12231306.

12) Mohamed TA, Hoffman RS, Fine IH, Packer M. Post-laser assisted in situ keratomileusis epithelial ingrowth and its relation to pretreatment refractive error. Cornea. 2011; 30(5): 550-2. doi: 10.1097/ICO.0b013e3182000ac3. PMID: 21598428.

13) Alió JL, El Aswad A, Vega-Estrada A, Javaloy J. Laser in situ keratomileusis for high hyperopia ( $>5.0$ diopters) using optimized aspheric profiles: efficacy and safety. J Cataract Refract Surg. 2013; 39(4): 51927. doi: 10.1016/j.jcrs.2012.10.045. PMID: 23375692.

14) Gil-Cazorla R, Teus MA, de Benito-Llopis L, Mikropoulos DG. Femtosecond laser vs mechanical microkeratome for hyperopic laser in situ keratomileusis. Am J Ophthalmol. 2011; 152(1): 16-21.e2. doi: 10.1016/j.ajo.2011.01.009. PMID: 21507378.

15) Antonios R, Arba Mosquera S, Awwad ST. Hyperopic laser in situ keratomileusis: Comparison of femtosecond laser and mechanical microkeratome flap creation. J Cataract Refract Surg. 2015; 41(8): 1602 9. doi: 10.1016/j.jcrs.2014.11.049. PMID: 26432116.

16) Ahn H, Kim JK, Kim CK, Han GH, Seo KY, Kim EK, et al. Comparison of laser in situ keratomileusis flaps created by 3 femto- second lasers and a microkeratome. J Cataract Refract Surg. 2011; 37(2): 349-57. doi: 10.1016/j.jcrs.2010.08.042. PMID: 21241920.

17) Vinciguerra P, Azzolini M, Radice P, Sborgia M, De Molfetta V. A method for examining surface and interface irregularities after photorefractive keratectomy and laser in situ keratomileusis: predictor of optical and functional outcomes. J Refract Surg. 1998; 14(2): S204-6. doi: 10.3928/1081-597X-1998040113. PMID: 9571554.

18) Kymionis GD, Kontadakis GA, Naoumidi I, Kankariya VP, Panagopoulou S, Manousaki A, et al. Comparative study of stromal bed of LASIK flaps created with femtosecond lasers (IntraLase FS150, WaveLight FS200) and mechanical microkeratome. Br J Ophthalmol. 2014; 98(1): 133-7. doi: 10.1136/bjophthalmol-2013-304023. PMID: 24187054.

19) De Ortueta D, Arba Mosquera S. Topographic stability after hyperopic LASIK. J Refract Surg. 2010; 26(8): 547-54. doi: 10.3928/1081597X-20100225-01. PMID: 20205358.

20) Krueger RR, Dupps WJ Jr. Biomechanical effects of femtosecond and microkeratome-based flap creation: prospective contralateral examination of two patients. J Refract Surg. 2007; 23(8): 800-7. PMID: 17985800.

21) Kim JH, Lee D, Rhee KI. Flap thickness reproducibility in laser in situ keratomileusis with a femtosecond laser: optical coherence tomography measurement. J Cataract Refract Surg. 2008; 34(1): 132-6. doi: 10.1016/j.jcrs.2007.08.036. PMID: 18165093.

22) Hamilton DR, Johnson RD, Lee N, Bourla N. Differences in the corneal biomechanical effects of surface ablation compared with laser in situ keratomileusis using a microkeratome or femtosecond laser. J Cataract Refract Surg. 2008; 34(12): 2049-56. doi: 10.1016/j.jcrs.2008.08.021. PMID: 19027558.

23) Holzer MP, Rabsilber TM, Auffarth GU. Femtosecond laser-assisted corneal flap cuts: morphology, accuracy, and histopathology. Invest Ophthalmol Vis Sci. 2006; 47(7): 2828-31. doi: 10.1167/iovs.051123. PMID: 16799021.

24) Kim WS, Jo JM. Corneal hydration affects ablation during laser in situ keratomileusis surgery. Cornea. 2001; 20(4): 394-7 doi: 10.1097/00003226-200105000-00011. PMID: 11333327.

25) Kezirian GM, Stonecipher KG. Comparison of the IntraLase femtosecond laser and mechanical keratomes for laser in situ keratomileusis. J Cataract Refract Surg. 2004; 30(4): 804-11. doi: 10.1016/j.jcrs.2003.10.026. PMID: 15093642.

26) Desai RU, Jain A, Manche EE. Long-term follow-up of hyperopic laser in situ keratomileusis correction using the Star S2 excimer laser. J Cataract Refract Surg. 2008; 34(2): 232-7. doi: 10.1016/j.jcrs.2007.09.019. PMID: 18242445.

27) El-Agha MS, Johnston EW, Bowman RW, Cavanagh HD, McCulley JP. Excimer laser treatment of spherical hyperopia: PRK or LASIK? Trans Am Ophthalmol Soc. 2000; 98: 59-66. PMID: 11190041, PMCID: PMC1298212.

28) Zadok D, Maskaleris G, Montes M, Shah S, Garcia V, Chayet A. Hyperopic laser in situ keratomileusis with the Nidek EC-5000 excimer laser. Ophthalmology. 2000; 107(6): 1132-7. doi: 10.1016/S01616420(00)00097-X. PMID: 10857833. 
29) Davidorf JM, Eghbali F, Onclinx T, Maloney RK. Effect of varying the optical zone diameter on the results of hyperopic laser in situ keratomileusis. Ophthalmology. 2001; 108(7): 1261-5. doi: 10.1016/S01616420(01)00588-7. PMID: 11425684.

30) Rashad KM. Laser in situ keratomileusis for the correction of hyperopia from +1.25 to +5.00 diopters with the Technolas Keracor 117C laser. J Refract Surg. 2001; 17(2): 113-22. PMID: 11310760.

31) Salz JJ, Stevens CA. LASIK correction of spherical hyperopia, hyperopic astigmatism, and mixed astigmatism with the LADARVision excimer laser system. Ophthalmology. 2002; 109(9): 1647-56; discussion 1657-8. doi: 10.1016/S0161-6420(02)01133-8. PMID: 12208711.

32) Llovet F, Galal A, Benitez-del-Castillo JM, Ortega J, Martin C, Baviera J. One-year results of excimer laser in situ keratomileusis for hyperopia. J Cataract Refract Surg. 2009; 35: 1156`-65. doi: 10.1016/j.jcrs.2009.03.014. PMID: 19545802. 